\title{
Surgical Management of Chronic Pancreatitis
}

\author{
Dilip Parekh $^{1}$ • Sathima Natarajan ${ }^{1,2}$
}

Received: 24 September 2015 / Accepted: 30 September 2015 / Published online: 22 October 2015

(C) Association of Surgeons of India 2015

\begin{abstract}
Advances over the past decade have indicated that a complex interplay between environmental factors, genetic predisposition, alcohol abuse, and smoking lead towards the development of chronic pancreatitis. Chronic pancreatitis is a complex disorder that causes significant and chronic incapacity in patients and a substantial burden on the society. Major advances have been made in the etiology and pathogenesis of this disease and the role of genetic predisposition is increasingly coming to the fore. Advances in noninvasive diagnostic modalities now allow for better diagnosis of chronic pancreatitis at an early stage of the disease. The impact of these advances on surgical treatment is beginning to emerge, for example, patients with certain genetic predispositions may be better treated with total pancreatectomy versus lesser procedures. Considerable controversy remains with respect to the surgical management of chronic pancreatitis. Modern understanding of the neurobiology of pain in chronic pancreatitis suggests that a window of opportunity exists for effective treatment of the intractable pain after which central sensitization can lead to an irreversible pain syndrome in patients with chronic pancreatitis. Effective surgical procedures exist for chronic pancreatitis; however, the timing of surgery is unclear. For optimal treatment of patients with chronic pancreatitis, close collaboration between a multidisciplinary team
\end{abstract}

Dilip Parekh

dparekh@surgery.usc.edu

1 Department of Surgery, Keck School of Medicine, University of Southern California, 1510 San Pablo Street, Los Angeles, CA 90033, USA

2 Department of Pathology, Kaiser Permanente Los Angeles Medical Center, Los Angeles, CA, USA including gastroenterologists, surgeons, and pain management physicians is needed.

Keywords Chronic pancreatitis · Surgery $\cdot$ Frey . Neuropathic pain $\cdot$ Total pancreatectomy $\cdot$ Puestow

\section{Introduction}

Chronic pancreatitis is an irreversible condition of the pancreas characterized by chronic progressive pancreatic inflammation, fibrosis, and scarring resulting in loss of both exocrine (acinar) and endocrine (islet cells) tissue. In the USA, chronic pancreatitis is cited as the seventh most commonly noted digestive disease diagnosis for hospitalization [1]. Annual healthcare costs associated with the treatment of chronic pancreatitis exceed $\$ 3$ billion in the USA, a significant financial burden [1]. Chronic pancreatitis is more common in men with the sex ratio (male/female) of 4.6. Men tend to have a higher frequency of alcohol-related pancreatitis while women have a higher risk of pancreatitis related to gallstones, endoscopic retrograde cholangiopancreatography (ERCP), and autoimmune diseases. In children, pancreatitis is usually associated with cystic fibrosis; however, in India, tropical calcific pancreatitis is more prevalent though the incidence appears to be decreasing [2]. Recent studies suggest that idiopathic pancreatitis may be more common than classic tropical calcific pancreatitis in India [2].

\section{Pathophysiology of Chronic Pancreatitis}

Trypsin metabolism and stellate cell activation play a central pathophysiological role in chronic pancreatitis [3, 4]. Whitcomb has proposed a model that describes chronic pancreatitis as a consequence of two hits [5]. The first hit is 
repeated attacks of acute pancreatitis that initiate the injury process (Table 1). Any insult that leads to premature activation of trypsin or persistence of active trypsin in the acinar cell of the pancreas makes the pancreas vulnerable to an acute inflammatory injury and may cause acute pancreatitis. The second hit in the progression to chronic pancreatitis is often associated with factors that promote chronic inflammation or modify the normal inflammatory response that leads to sustained activation of pancreatic stellate cells resulting in chronic fibrosis $[4,5]$.

Pancreatic stellate cells (PSC) mediate the fibrotic destruction of the pancreatic gland that is found in chronic pancreatitis. PSC are activated either directly by toxins such as alcohol [3] or by cytokines locally produced during the necroinflammatory process associated with acinar cell destruction during an attack of acute pancreatitis [6]. PSC leads to the formation of collagen and deposition of the extracellular matrix proteins in the interstitial space that leads to acinar and ductal cell destruction. The ultimate consequence of this is progressive loss of lobular architecture and duct structure of the pancreas. This fibrotic destruction of the pancreas is irreversible and the associated morphological and structural changes cause loss of exocrine and endocrine function leading to diabetes and pancreatic insufficiency. The mechanism of chronic fibrosis seen in chronic pancreatitis may be similar to that seen in liver cirrhosis as both appear to be mediated by abnormal activation and functioning of stellate cells $[3,7]$.

\section{Etiology of Chronic Pancreatitis}

The TIGAR-O system for classification of chronic pancreatitis is presently the most clinically relevant and widely used system [8]. TIGAR-O system incorporates new insights on various risk factors for chronic pancreatitis and consists of six groups including toxic, metabolic particularly alcohol, idiopathic, genetic, and autoimmune (Table 1). The NAPS2 study in the USA showed that $45 \%$ of pancreatitis in the USA is associated with alcohol abuse, $29 \%$ of patients fall into the idiopathic category, autoimmune pancreatitis accounts for $2.2 \%$ and an underlying genetic disorder for about $9 \%[9$, 10]. Advances over the past decade have indicated that a complex interplay between environmental factors, genetic predisposition, and alcohol abuse and smoking lead towards the development of chronic pancreatitis.

A relationship between alcohol consumption and chronic pancreatitis has been well recognized. Epidemiological studies have shown that ingestion of approximately $80 \mathrm{~g}$ of alcohol per day for a minimum of 6 to 12 years is required for development of symptomatic chronic pancreatitis [2,11]. Recent data suggest that consumption of lesser quantities of alcohol may also lead to progression of chronic pancreatitis. The MAnneheim classification system of chronic pancreatitis has
Table 1 TIGAR-O system of classification of chronic pancreatitis

- Toxic-metabolic
Alcoholic
Tobacco smoking
Hypercalcemia
Hyperlipidemia
Medications
Toxins
- Idiopathic
Idiopathic
Tropical
- Genetic
Autosomal dominant
PRSS1 mutation
Autosomal recessive/modifier genes
CFTR mutations
SPINK1 mutations
Anionic trypsinogen gene mutations (PRSS2)
- Autoimmune
- Recurrent and severe acute pancreatitis
Post-necrotic (post-severe acute pancreatitis)
Pancreatic divisum
puct obstruction (e.g., tumor, duct injury from post-surgery,
Obsizing pancreatitis, post-trauma)

therefore grouped alcohol consumption into patterns of moderate ( $<20$ g ethanol per day), increased ( $20-80 \mathrm{~g}$ ethanol per day), or excessive ( $>80 \mathrm{~g}$ ethanol per day) [12]. It is interesting that while alcohol is the most commonly recognized factor in the development of chronic pancreatitis, only about $10 \%$ of chronic alcoholics develop chronic pancreatitis [13]. Recent studies have demonstrated the importance of genetic mutations particularly in SPINK1, CFTR, and the x-linked CLDN genes and polymorphisms that confer susceptibility for alcohol-mediated injury on the pancreas and may explain why only a subset of the population of chronic alcoholics develop chronic pancreatitis $[11,14]$. Smoking aggravates the deleterious effect of alcohol on the pancreas. Recent studies have suggested that smoking has a dose-dependent effect in potentiating the development of alcoholic chronic pancreatitis $[11,15]$. When a threshold of 15 smoking pack-years is reached, chronic alcoholic pancreatitis was diagnosed a decade earlier, and at a nicotine consumption threshold of 20 pack-years, up to $76 \%$ of patients presented with pancreatic calcifications and duct changes [16]. These studies suggest that alcohol sensitizes the pancreas to other external factors such as smoking, diet, and genetic predisposition which interact to augment ethanol toxicity in vivo. It is interesting that smoking may also be an independent risk factor in chronic pancreatitis. For example, a recent study reported that 
cigarette smoking increases the risk of pancreatic calcifications in late onset idiopathic chronic pancreatitis in a population that did not consume any alcohol [17].

In 1952, Comfort and Steinberg [18] first described hereditary chronic pancreatitis as an autosomal dominant disease. In 1996, the hereditary chronic pancreatitis disease gene was mapped to chromosome $7 \mathrm{q} 35$, which encodes the cationic trypsinogen gene (PRSS1), and the first mutation, R122H, was detected [19]. In the past decade, several genetic mutations have been described that appear to play a role both in hereditary and in acquired chronic pancreatitis including alcoholic, idiopathic, and tropical chronic pancreatitis. The majority of the genetic mutations identified induce susceptibility to chronic pancreatitis by mechanisms that lower threshold for trypsin activation or induce sustained trypsin activity in the pancreas. The gene locus that includes the PRSS-1 and PRSS2 genes have been shown to be associated with reduced expression of trypsinogen [5]. Mutations in PRSS-1 also lead to increased trypsinogen activation and decrease trypsin degradation $[4,5,8,14]$. SPINK-1 blocks active trypsin and further activation of trypsinogen. Mutations in SPINK1 lead to failure of trypsin degradation [5]. The chemotrypsin $\mathrm{C}$ gene (CTRC) facilitates intracellular trypsin degradation. Mutations in this gene lead to failure of trypsin degradation $[4,5,14]$. The CaSR gene regulates intracellular calcium levels. Mutations in this gene lead to high intracellular calcium levels that block trypsin degradation $[4,5,14]$. All of the above genetic mutations have a higher prevalence in patients with chronic pancreatitis compared to the general population. For example, susceptibility mutations in the SPINK-1 gene are associated with tropical calcific pancreatitis prevalent in India [20]. Similarly, genetic mutations in the CTRC gene lead to a higher risk for tropical and idiopathic chronic pancreatitis. Mutations in the CaSR gene and the X-linked CLDN2 gene are associated with a high susceptibility of alcoholic pancreatitis in men. The function of the CLDN2 gene is presently not clear [21].

Multiple etiological factors and the complex pathophysiology of chronic pancreatitis suggest that the term chronic pancreatitis may encompass many different diseases with each requiring its own tailored treatment. As we describe in the subsequent sections of this article, medical and surgical approaches lead to variable outcomes and the treatment efficacy in an individual patient cannot be predicted prior to the intervention. Integration of new findings from genetic analysis into therapeutic approaches for chronic pancreatitis may allow for development of more effective treatments that are better monitored with biomarkers to maintain pancreatic function and prevent progression of disease in the future.

\section{Diagnosis of Chronic Pancreatitis}

The diagnosis of chronic pancreatitis is confirmed by imaging studies in a patient with an appropriate clinical presentation.

ERCP Previously, ERCP was considered the gold standard for the diagnosis of chronic pancreatitis. The Cambridge criteria were developed at an expert consensus conference in 1984 to standardize and classify endoscopic retrograde pancreaticographic changes in chronic pancreatitis. Changes are graded as normal (0), equivocal (1), mild (2), moderate (3), or severe (4) depending on the changes observed in the main pancreatic duct and side branches. In recent years, MRI and endoscopic ultrasonography (EUS) have transplanted ERCP as the imaging modalities of choice. The disadvantages of ERCP include the risk of development of acute pancreatitis and the failure of the study to evaluate the pancreatic parenchyma.

Computerized Tomography (CT) CT scan is often the first modality that is obtained in a patient with abdominal pain. In patients with severe pancreatitis, findings such as calcifications, atrophy, ductal dilatation, and complications of chronic pancreatitis such as pseudocysts and biliary dilatation may be seen. In a patient with suspected chronic pancreatitis, an MRI with MRCP would be the next follow-up study at our institution.

MRI with MRCP MRCP provides a noninvasive evaluation of ductal changes and has a higher resolution and sensitivity than a CT scan. MRI has been reported to have a high sensitivity ( $88 \%$ ), specificity (98\%), and accuracy (91\%) compared to ERCP in identifying pathological ductal changes in patients with moderate to severe changes of chronic pancreatitis as assessed by the Cambridge criteria [22]. While MRI with MRCP is a very useful study for patients with advanced changes of chronic pancreatitis, the sensitivity is as low as $25 \%$ in patients with small duct disease or minimal change chronic pancreatitis. It is this subgroup of patients with early disease or small duct disease that provides a diagnostic challenge with noninvasive imaging. However, because of its utility in patients with moderately severe and advance chronic pancreatitis, MRI with MRCP has replaced ERCP as the initial diagnostic imaging study of choice in the workup of patients with chronic pancreatitis.

Endoscopic Ultrasonography EUS is helpful in identifying early changes of chronic pancreatitis prior to the development of calcifications, ductal dilatation, and significant atrophy of the pancreas. In addition to that, EUS may also be helpful in identifying patients with small duct disease. The accuracy of EUS in chronic pancreatitis relies on quantitative and qualitative parenchymal and ductal criteria that were established at an 
international consensus conference and are presently known as EUS-Rosemont criteria. Most centers use at least five EUSRosemont diagnostic criteria to diagnose chronic pancreatitis [23]. The major limitation of EUS is that it is highly operator dependent. Furthermore, since most surgeons have limited experience with EUS and the surgical anatomy is often difficult to interpret from EUS images, this modality as the sole imaging modality is not very helpful for the planning of surgical treatment of chronic pancreatitis. If the $\mathrm{CT}$ and MRI imaging studies are equivocal, then EUS is useful for establishing the diagnosis of chronic pancreatitis. If surgical treatment is a consideration, then the patient may require an ERCP for further evaluation.

Newer Imaging Options Secretin-enhanced MRCP (SMRCP) [24] and EUS elastography [25] are two new diagnostic modalities that are currently being evaluated for their role in the diagnosis of chronic pancreatitis. Secretin administration stimulates pancreatic juice secretion filling the pancreatic side branch ducts and the main pancreatic duct. Side branch ectasia, mild duct dilatation, and irregularities are often better appreciated with S-MRCP. Two-dimensional MR is repeated every $30 \mathrm{~s}$ for $10 \mathrm{~min}$ after administration of secretin for S-MRCP and pre- and post-secretin images are then compared for changes in the main pancreatic duct caliber, visualization of main and side branches, sphincter of Oddi function, and the duodenal filling. S-MRCP has potential for improving the diagnosis of chronic pancreatitis; however, standardization of S-MRCP reporting including duodenal filling volume, ductal changes, and other features is required to improve its utility [26].

EUS elastography is a real time EUS-guided modality that analyzes the tissue stiffness of the pancreas quantitatively and is currently under investigation for its efficacy in the diagnosis of chronic pancreatitis. Quantitative elastography shows sensitivity and specificity of $91 \%$ for the diagnosis of chronic pancreatitis. EUS elastography also allows quantification of the degree of pancreatic fibrosis and thus severity of the disease [25].

Presently, these two studies are not in widespread use; however, early experience suggests that they may have tremendous potential in the diagnosis of patients with early chronic pancreatitis and small duct disease.

\section{Treatment of Chronic Pancreatitis}

Surgical treatment of chronic pancreatitis is limited to the complications associated with this disorder (Table 2). Steatorrhea and diabetes mellitus are the commonest complications associated with chronic pancreatitis. While there is some literature to suggest that early surgical intervention may ameliorate or delay the development of diabetes and
Table 2 Indications for surgery in chronic pancreatitis

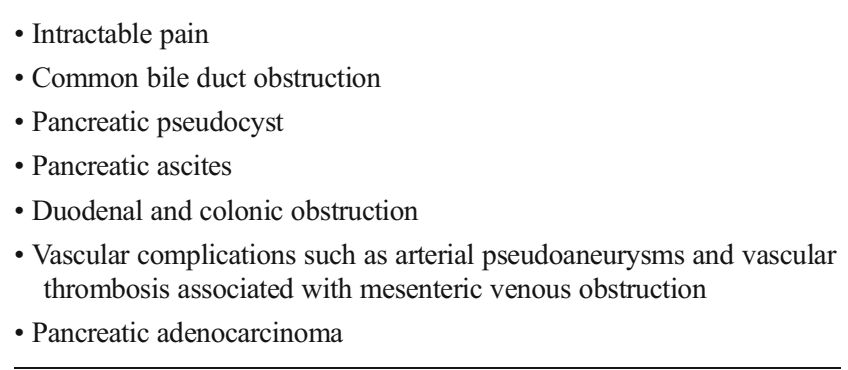

pancreatic malabsorption [27], current practice dictates that diabetes and steatorrhea are expectantly treated with medical therapy and the role of surgery in an otherwise asymptomatic patient with early diabetes is controversial at best. Chronic intractable pain is usually the single most common indication for surgical intervention and is also the most disabling consequence of chronic pancreatitis.

\section{Pain in Chronic Pancreatitis}

Pain in chronic pancreatitis has a variable presentation from intermittent episodic occurrence to severe continues chronic pain that leads to a substantial limiting of daily activity and lifestyle of the patient. Chronic pain is also one of the commonest symptomatic manifestation of chronic pancreatitis, and its reported prevalence is 50 to $85 \%$ [1]. The mechanism of pain in chronic pancreatitis is controversial as is its treatment.

One of the earliest proposed mechanisms for the pain in chronic pancreatitis that also led to the development of the Peustow procedure is the theory that the blockage of the main pancreatic duct in the head of the pancreas leads to pancreatic duct hypertension and pain. Documentation of pancreatic duct hypertension is controversial as some early studies demonstrated elevated pressures in the pancreatic duct in patients with chronic pancreatitis; however, subsequent studies failed to show a difference in the level of pancreatic duct pressures in patients with and without pain with chronic pancreatitis [28]. Furthermore, results from studies that have utilized endoscopic manometry have been equivocal with some studies showing evidence of elevated intraductal pressures while other studies do not [28-31]. Today, it is considered that pancreatic duct hypertension may play a role in some patients; however, it is unlikely that this is the primary mechanism in most patients. Furthermore, outcomes of the Peustow procedure as discussed below demonstrate that only a small subset of patients benefit from the drainage procedure. It has also been proposed that the fibrosis of the pancreatic parenchyma and peripancreatic soft tissues produces a compartment-like syndrome. This may cause secondary ischemia and development of chronic pain similar to the pathophysiology underlying muscular 
compartment syndrome. While there is some animal data to support this, these findings have not been confirmed in human studies $[28,32]$. Based on the evidence at present, it would indicate that while ductal hypertension and glandular hypertension may be present in some patients, it is unclear whether this is a significant factor to explain the pain in the vast majority of patients with chronic pancreatitis.

In the past decade and a half, there has been intense investigation towards a neurobiological understanding of pain in chronic pancreatitis [33, 34] (Fig. 1). Reported changes in pancreatic nerves in chronic pancreatitis include infiltration of inflammatory cells, neural edema, an increase in neural density, neural hypertrophy and sprouting, glial proliferation, and neuritis of the intrapancreatic nerves. These changes collectively known as pancreatic neuropathy have been strongly associated with clinical pain scores and therefore suggest that pancreatic neuropathy may play an important factor role in the pathogenesis of pain in chronic pancreatitis $[35,36]$. Furthermore, evidence suggests that the pancreatic neuropathy may lead to the remodeling of intrapancreatic nerve innervation [37].

Associated with changes in pancreatic neural innervation consistent with a pancreatic neuropathy, there are also changes in nociception in the pancreas. Nociceptive markers such as nerve growth factor and brain-derived neurotrophic factor and many proinflammatory cytokines are upregulated in pancreatic tissue in chronic pancreatitis, and in some cases this upregulation has been associated with increased pain intensity and/ or frequency. These biochemical changes render the nociceptors more sensitive to further pain stimulation, thereby reducing the threshold for activation in response to pain, an increase in the response to a given pain stimulus, or the appearance of spontaneous activity of the pain receptors. This sensitization, called peripheral sensitization, results in an abnormal increase of pain signals to the spinal cord. A sustained and increased peripheral nociceptive drive from the pancreas may result in an increased responsiveness of central paintransmitting neurons in the dorsal horn of the spinal cord.
Fig. 1 Mechanism of pain in chronic pancreatitis. The neuropathic pain syndrome involves molecular and morphological alterations at intrapancreatic (peripheral) and extrapancreatic (dorsal root ganglia, spinal cord, brainstem, and cerebrum) sites. Reproduced with permission from Demir et al Langenbeck's Archives of Surgery, 2011. 396(2): p. 151160 [33]

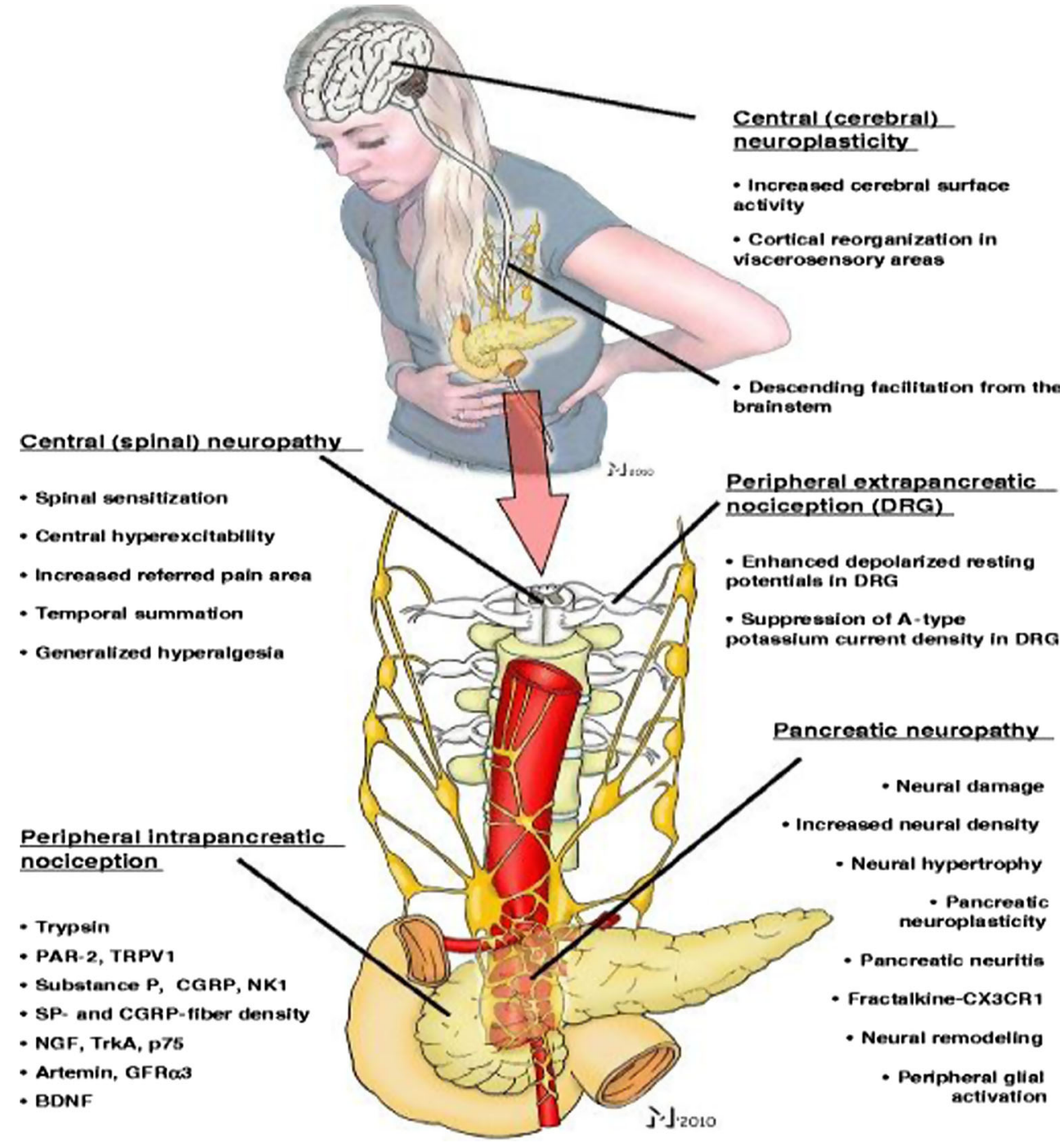


This phenomenon is known as central sensitization and may lead to clinical conditions of abnormal pain perception frequently observed in chronic pancreatitis particularly in patients on long-standing narcotic medications such as allodynia (generation of pain from a physiological or non-noxious stimulus) and inflammatory hyperalgesia (amplified pain response to normal or minimal pain stimuli) $[30,38]$.

Experimental pain studies have shown that chronic pain and hyperalgesia are associated with functional reorganization of the cerebral cortex. Compared to healthy controls, chronic pancreatitis patients showed reorganization of the brain areas that are involved in visceral pain processing including the insula, the secondary somatosensory cortex, and the cingulate gyrus, changes that are similar to that observed in the phantom pain syndrome [39]. Diffusion-weighted MRI studies of the brain in chronic pancreatitis have shown that the microstructural changes in the insula and frontal brain areas are correlated with clinical pain intensity and functional scores [40]. Patients with continuous and daily pain demonstrated the most severe microstructural abnormalities compared to patients with intermittent episodic pain [40]. These findings suggest that a central brain neurodegenerative response develops in chronic pancreatitis patients with chronic severe pain.

\section{Medical Treatment of Pain in Chronic Pancreatitis}

Abstinence of alcohol and smoking is a very important adjunct to medical and surgical treatment for chronic pancreatitis. Continuation of smoking or ingestion of alcoholic beverages leads to progressive damage to the pancreas with an increase in severity of the underlying chronic pancreatitis. Persistent alcohol abuse and smoking also increase failure rates of previous medical or surgical treatments. The role of antioxidant treatment and drugs such as pregabalin is controversial and has been shown to have a modest effect at best [41]. Patients who develop significant pain usually progress to endoscopic treatments. Endoscopic treatment may be indicated in patients who have a dilated pancreatic duct with stones or a dominant stricture in the duct. Patients with small duct disease, multiple strictures, and multiple calculi throughout the gland are poor candidates for endoscopic treatment.

Endoscopic therapy involves stenting of pancreatic duct strictures and removal of stones. Extracorporeal shockwave lithotripsy (ESWL) is usually required to fragment stones in the pancreatic duct and endoscopic mediated stent placement and/or dilatation of the pancreatic duct is performed for the strictures. With ESWL (alone or combined with endoscopic drainage), more than $70-80 \%$ of patients have short-term pain relief and about $60 \%$ of patients have long-term pain relief (2-5 years) $[42,43]$. The European Society for Gastrointestinal Endoscopy (ESGE) recommends ESWL/ERCP as the first-line interventional option for patients with uncomplicated chronic pancreatitis. The recommendations are that after 6 to 8 weeks of treatment, if the clinical response is unsatisfactory, then a surgical option should be considered [44].

There are only two prospective randomized studies with small patient numbers that have compared medical and surgical approaches and both studies show that surgical treatment is more durable and effective than endoscopic treatment for chronic pancreatitis. Dite et al. [45] found complete pain relief in $37 \%$ of patients undergoing surgery versus $14 \%$ of patients receiving endoscopic treatment. This study did not include shockwave lithotripsy, cumulative stentings, or repeat treatments after recurrence of symptoms in the endoscopic treated arm. Cahen et al. [46] found in patients with chronic pancreatitis and pancreatic duct obstruction that surgical drainage is more effective than endoscopic treatment during a 2-year follow-up. The benefits of surgery were demonstrated by more rapid, effective, and sustained pain relief, a better state of health, and few procedures. The mean pain score between the treatment groups was almost 24 points, a substantial difference that reflected the difference between having no pain and having pain daily.

\section{Surgical Procedures to Treat Pain in Chronic Pancreatitis}

Longitudinal studies show that surgery will eventually be required in about 40 to $75 \%$ of patients with chronic pancreatitis during the course of their disease [43] (Fig. 2). At present, conservative medical management is usually the first step and progression to severe and intractable pain is considered necessary by many clinicians before a referral to surgery is made. As we will show some data later in this review, this approach is currently being questioned and the Dutch pancreas group is currently conducting a prospective randomized study of early surgery versus a step-up approach of conservative and endoscopic treatment prior to surgery [47]. Over the past five decades, several surgical procedures have evolved to address the different subtypes of patients with chronic pancreatitis. Historically, the Whipple operation was the standard procedure for chronic pancreatitis. Development of drainage procedures led to these procedures coming into vogue [48, 49]; however, the high failure rate of these procedures in many patients led to the appreciation that the head of the pancreas may be a pacemaker for pain especially in patients with inflammatory masses in the head of the pancreas. This led to the development of newer procedures such as the Frey [50] and Beger procedure [51]. There is a subgroup of patients with small disease in whom these procedures are ineffective, and in this patient population, the concept of a total pancreatectomy with islet cell transplantation has evolved as a viable option [52]. It is interesting to note as we will emphasize in this review that patients who have long-standing intractable and 
Fig. 2 Algorithm for the management of painful chronic pancreatitis

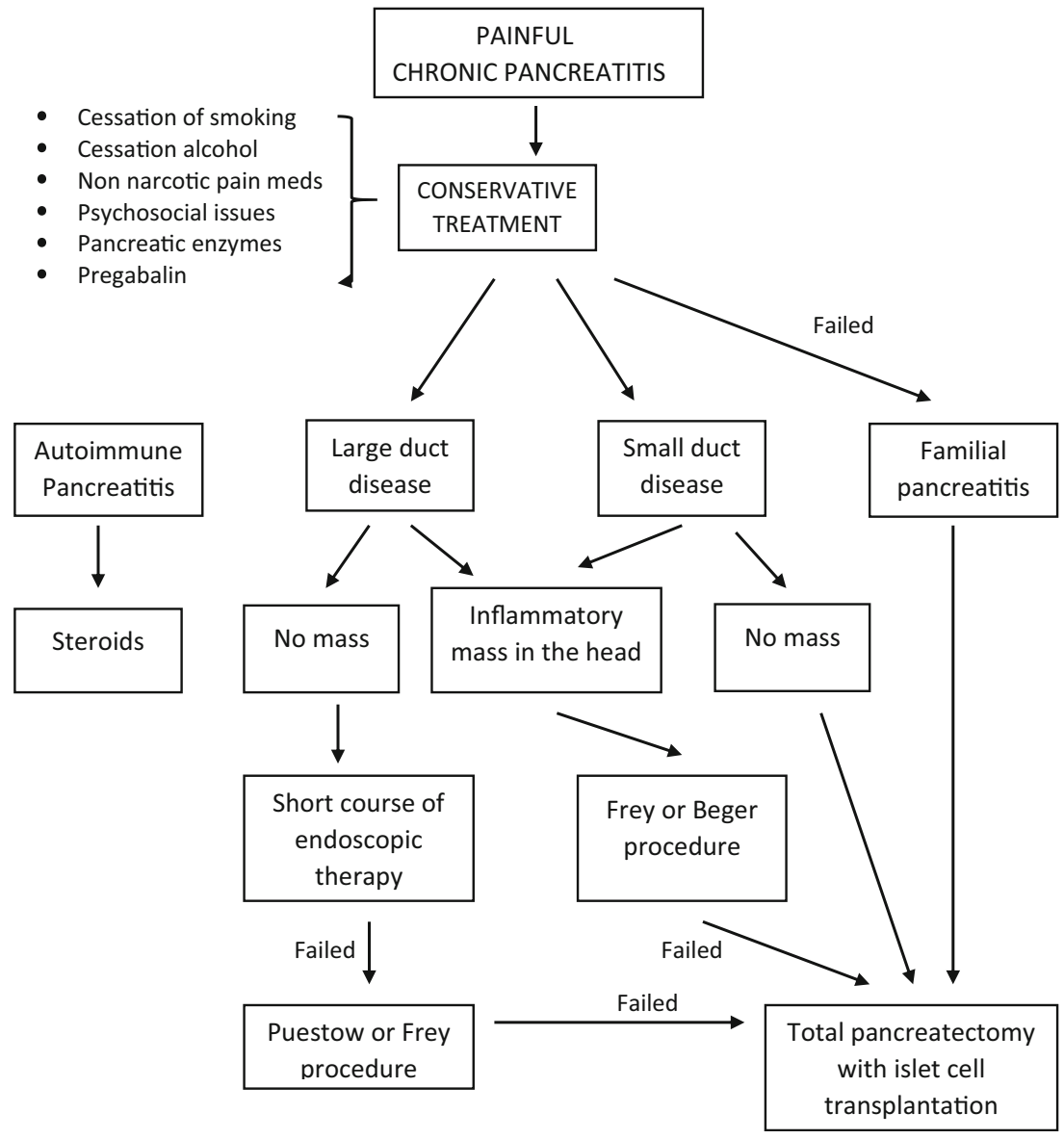

In this procedure, the pancreatic duct is opened along the anterior surface of the pancreas from the tail extending as far into the head as possible. It is the proximal extent into the head that determines a good outcome of this procedure, and an attempt should be made to get to within 0.5 to $1 \mathrm{~cm}$ of the ampulla to provide adequate drainage to the duct in the head of the pancreas. Furthermore, in a significant number of patients, calcified pancreatic stones are going to be found in the head of the pancreas and clearing of the duct by removal of the stones is important for good pain relief. After the duct has been widely opened and of all stones cleared, a Roux-en-Y jejunostomy is sutured side to side to the pancreas. The procedure is associated with a low morbidity and mortality (about $1 \%$ ). Pain relief is reported in up to $80 \%$ of patients (with a range of 30-100 \%) in the immediate postoperative period. In follow-up studies, however, the pain relief is shown to disappear in up to $40 \%$ of patients, particularly in patients with alcoholic pancreatitis who undergo recidivism of their alcoholism [54]. Most patients who develop recurrent pain are those who resume heavy alcohol consumption. Complete abstinence from alcohol and smoking has been suggested as an alternative to reoperation after a Puestow procedure and up to $30 \%$ of patients who stopped all alcohol intake have 
improvement in pain symptoms [54]. In a study by Prinz and Greenlee, 23 of 87 patients undergoing Puestow procedure ceased all alcohol intake, and 21 of them remained pain free; however, 14 of the 16 who achieved no pain relief had continued to drink alcohol [55].

This procedure is not indicated in patients with an inflammatory mass in the head of the pancreas, small duct disease, genetic etiology for the chronic pancreatitis, and many patients with idiopathic pancreatitis who do not have very dilated ducts. Furthermore, outcome from surgery is strongly influenced by continued drinking and smoking, and supportive management in the postoperative period that includes rehabilitation programs for alcohol and narcotic addiction and smoking cessation programs is important for durable long-term results for the Puestow procedure for chronic pancreatitis.

\section{Duodenum-Preserving Pancreatic Head Resection (DPPHR)}

The surgical outcomes of pancreatic duct drainage procedures and the Whipple operation led to the realization that addressing the pancreatic head is critical for long-term pain relief from chronic pancreatitis. This has led to the concept of the head of the pancreas being a pacemaker for pain in chronic pancreatitis [56]. It has been proposed that this pacemaker function of the head of the pancreas responsible for the pain in chronic pancreatitis is best addressed by the Whipple operation and other procedures directed towards removing a portion of the head of the pancreas. This pacemaker concept attempts to account for the superior results of procedures that remove the head of the pancreas compared to pancreatic drainage procedures in the treatment of pain for chronic pancreatitis. While the Whipple operation was shown to be effective for the treatment of intractable pain in chronic pancreatitis, the significant long-term morbidity of this procedure led to the development of the Frey and the Beger procedures in which varying amounts of the head of the pancreas is removed with preservation of the duodenum and the bile duct.

\section{The Frey Procedure}

Frey and Smith describe a new operation for management of pain of chronic pancreatitis in 1987 [50]. In this procedure, the anterior head of the pancreas incorporating all of the pancreatic tissue including the major and minor pancreatic ducts is excised and the main pancreatic duct is then longitudinally opened and a Roux-en-Y limb is brought up to complete a pancreaticojejunostomy. Key steps in the performance of the Frey procedure include preservation of the pancreatic neck and the posterior pancreatic head. The posterior limit of resection is the back wall of the opened duct of Wirsung and minor pancreatic duct to the uncinate process. All intervening and overlying tissue in the pancreatic head including the duct of
Santorini is excised. The Frey procedure has excellent perioperative outcomes in reported studies with morbidity ranging between 7.5 and $39 \%$ and mortality rates between zero and $2.4 \%$ [57-65].

In their initial experience, Frey and Amikura reported the results in 50 cases with a mean follow-up of 3.5 years. Seventy-five percent of patients demonstrated excellent pain relief, $13 \%$ had improved symptoms, and only $30 \%$ showed no improvement in their pain after the Frey procedure. With respect to pancreatic function, only $11 \%$ had progression of their diabetes and none of the patients had worsening of the exocrine function [65]. In a similar study, Negi et al. reported pain relief in $75 \%$ of patients undergoing a Frey procedure, $7 \%$ develop diabetes mellitus de novo, and none of the patients showed deterioration of pancreatic exocrine function over a median follow-up period of 6.4 years [58]. Gestic et al. in a more recent publication of 73 patients undergoing a Frey procedure found that $91 \%$ of patients had complete pain relief after a median postoperative follow-up of 77 (range 12-204) months [63].

\section{Beger's Procedure}

In 1972, Hans Beger performed the first duodenumpreserving pancreatic head resection, or DPPHR. Key steps in the DPPHR include identifying and preserving the posterior branch of the gastroduodenal artery which provides blood flow to the duodenum, intrapancreatic common bile duct, and pancreaticoduodenal groove. The neck of the pancreas overlying the portal and superior mesenteric vein is transected and all of the head of the pancreas except pancreatic tissue along the inner aspect of the duodenum is resected [51].

Beger et al. reported excellent surgical outcomes after their 26-year experience of this procedure in 594 patients with chronic pancreatitis with the hospital mortality of only $0.8 \%$. Furthermore, in a study on the long-term outcome in a group of 303 patients, $91.7 \%$ were pain free after a median follow-up of 5.7 years. These results show that the Beger procedure is a safe and effective procedure in selected patients with an enlarged inflammatory mass in the head of the pancreas associated with pain in chronic pancreatitis [51].

\section{Comparison of Pancreaticoduodenectomy, the Frey Procedure, and the Beger Procedure for Treatment of Pain in Chronic Pancreatitis}

Izbicki et al. reported on the first prospective randomized controlled study comparing the Frey procedure to a pancreaticoduodenectomy [66]. In the interim results reported 24 months after surgery, the rate of in-hospital complications was $19.4 \%$ in the Frey group and $53.3 \%$ in the Whipple group, including delayed gastric emptying in 9 of 30 patients ( $30 \% ; p<0.05$ ). The pain score decreased by $94 \%$ after Frey 
procedure and by $95 \%$ after Whipple operation. Global quality of life improved by $71 \%$ in the Frey procedure and by $43 \%$ in the Whipple group $(p<0.01)$ [66]. Strate et al. reported on an 8-year follow-up results of this study. There was no difference between the two groups with respect to quality of life and pain score at 8-year follow-up after the surgical procedure [60]. Twenty-five percent of patients continued to drink in the long term, and in this group the pain score and global quality-of-life scores were lower compared to nonalcoholic patients.

Farkas et al. compared the Beger procedure to a pancreaticoduodenectomy in a randomized trial [67]. The Beger procedure was associated with a significantly lower morbidity and improvement in body weight, operating time, and duration of hospital stay compared to the Whipple operation. The outcome of the two procedures on pain relief was similar with approximately $85 \%$ of patients' pain free after the two procedures in the study. Similarly, Buchler et al. randomized patients to the Beger procedure or a Whipple operation [68]. At 14-year follow-up, there were no significant differences in global health status, endocrine exocrine insufficiency, and effect of the two procedures on the pain from chronic pancreatitis [68].

Izbicki et al. randomized 74 patients with chronic pancreatitis with an inflammatory mass in the head of the pancreas and severe recurrent pain attacks requiring opiates to either a Beger $(n=38)$ or a Frey procedure $(n=36)$ [69]. The Frey procedure group had a significantly lower morbidity $(9 \%)$ compared to the Beger procedure (20\%); there was no mortality in this study. At 2-year follow-up after surgery, the global quality-of-life score significantly increased in both groups from a median preoperative score of 28 to 86 and the pain score was significantly reduced by an average of $86 \%$ from a preoperative score of 62 to 23 [61]. Bachmann et al. recently reported a 16-year follow-up on this study [57]. In the surviving patients at 16-year follow-up, the median pain score and global quality-of-life index were found to be similar in patients who underwent a Beger or a Frey procedure. The subgroup of patients with continued alcohol consumption had a significantly lower cognitive functioning, emotional functioning, and global quality-of-life score ( 83 vs. 33) and pain score ( 3 vs. 50 ). The prevalence of endocrine and exocrine insufficiency and survival at 16-year follow-up was similar in this study compared to a conservatively treated group of patients reported in the literature with chronic pancreatitis [57].

Yin and colleagues performed a meta-analysis and selected 15 trials out of 185 articles reviewed (5 randomized and 10 nonrandomized) comparing duodenum-preserving pancreatic head resections (Beger and Frey operations) with standard resections (pancreaticoduodenectomy and pyloruspreserving pancreaticoduodenectomy) in patients with pain and chronic pancreatitis. The studies had to meet the following inclusion criteria: (1) patients presenting with pancreatic head mass ( $\geq 35 \mathrm{~mm}$ ) based on CT evaluation or with intractable pain and obstruction of the common bile or the pancreatic duct, (2) patient had no contraindication for surgical management of chronic pancreatitis, (3) postoperative pain relief and postoperative morbidity were assessed as outcome measures of the effect of the treatment, (4) the study was published as a full-length article, and (5) the study included at least 30 patients [62].

In the meta-analysis, the short- and long-term results of the Beger and Frey operations for global quality of life were significantly better than the standard resections such as the Whipple operation. Subgroup analysis, however, reveals the Beger operation achieves significantly better postoperative pain relief with perioperative morbidity similar to the standard resections, whereas the Frey operation has significantly lower perioperative morbidity but similar postoperative pain relief as the standard resection techniques [62].

Three decades of randomized and non-randomized trials have shown that both the Beger and the Frey procedures are at least as effective as the Whipple operation for the management of intractable pain in chronic pancreatitis. The overall morbidity of the Frey procedure is significantly less than the Whipple operation and the Beger procedure, and the global quality-of-life indicators are similar between the Frey and the Beger procedure after an extended length of follow-up of over 15 years. These two procedures are the treatment of choice in patients with an inflammatory mass in the head of the pancreas associated with chronic pancreatitis, and the choice of the individual procedure should be largely dictated by the local surgical expertise in the treating institution.

\section{Total Pancreatectomy with Islet Autologous Transplantation (TP-IAT)}

\section{Indications for TP-IAT}

A subgroup of patients with chronic pancreatitis have recalcitrant pain that is resistant to medical and surgical treatments. In 1977, investigators at the University of Minnesota School of Medicine pioneered the first total pancreatectomy with islet autologous transplantation (TP-IAT) [70]. Since then, TPIAT has slowly evolved into the mainstream as a therapeutic option for patients with recalcitrant pain from chronic pancreatitis. At present, approximately 12 centers in the USA have an islet isolation laboratory and offer the procedure. In addition to that, the technology is evolving for remote isolation and transplantation in centers that do not have an islet isolation laboratory.

Selection criteria for patients with TP-IAT are controversial. A recent consensus conference in 2014 suggested that the primary indication for TP-IAT is to treat intractable pain in patients with impaired quality of life due to chronic 
pancreatitis or recurrent acute pancreatitis in whom medical, endoscopic, and prior surgical therapy has failed. Patients with active alcoholism, active illicit substance abuse, untreated or uncontrolled psychiatric illness, and patients with poor support networks are a relative contraindication. Patients who have C-peptide negative diabetes, type I diabetes, portal vein thrombosis, and portal hypertension or significant liver disease should not undergo transplantation [71]. A recent consensus conference at the National Institutes of Health identified five criteria that have to be fulfilled [72]:

1. The diagnosis of chronic pancreatitis has to be confirmed by recognized morphological criteria on CT scan and endoscopic ultrasound or they should be histopathology present with a compatible clinical history and documented hereditary pancreatitis

2. daily narcotic dependence or chronic pain substantially impairing quality of life

3. complete evaluation to rule out reversible causes of pancreatitis

4. failure to respond to maximum medical and endoscopic treatment

5. adequate islet cell function (nondiabetic or C-peptide positive)

Patients who have failed surgical procedures and patients who have chronic pancreatitis with small duct disease are generally accepted indications for TP-IAT. Indications for surgery in patients with alcoholic pancreatitis, large duct disease, pancreatic duct stones, and diffuse calcifications are more controversial. A recent publication from Wilson and colleagues from the University of Cincinnati reported on the largest long-term follow-up study with TP-IAT, and in this study, approximately $75 \%$ had idiopathic pancreatitis, $14 \%$ had chronic pancreatitis from a genetic disorder, $9 \%$ with pancreatic divisum, and only $3 \%$ had alcoholic pancreatitis. Forty percent of patients in this study had a prior pancreatic operation including a pancreaticoduodenectomy, a Puestow or Frey procedure, and distal pancreatectomy [73].

\section{Technique for TP-IAT}

The techniques for TP-IAT have been increasingly standardized [52, 70, 73-76]. A key surgical consideration is minimizing the warm ischemia time during the total pancreatectomy. To this effect, an essential surgical principle during the total pancreatectomy is to maintain the arterial inflow and venous outflow in the dissected pancreas specimen to the very end. This is accomplished by preserving the splenic artery and vein and the gastroduodenal artery during the resection and litigating these structures at the very end when the specimen is nearly out. The spleen is not preserved to minimize prolonging the ischemic time associated with the additional time required in dissecting the body and tail off the splenic vessels and the associated ischemia of the body and tail from the devascularization. With these caveats, the total pancreatectomy is performed along standard surgical principles.

The explanted pancreas is then placed in an ice-cold preservation solution and the splenic artery, gastroduodenal artery (GDA), and pancreatic ducts are flushed with ice-cold preservation solution. Next, the pancreatic duct is distended by infusion with a mixed enzyme solution of collagenases and proteases and the gland is manually dissociated using scissors into small 5-mm-size chunks of tissue. The entire collected tissue with enzyme solutions is then placed into a digestive chamber and the digest is collected for centrifugation. The final cell palette with the islets is then suspended in albumin ready for injection into the portal venous system.

\section{Results for TP-IAT}

Endocrine Function After autologous islet cell transplantation, approximately a third of the patients remain insulin independent, a third of the patients will maintain partial islet cell function, and the rest of the patients will have minimal islet cell function. The incidence of unstable severe brittle diabetic state that predisposes patients to episodes of hypo- and hyperglycemia associated with complete graft failure occurs in up to $30 \%$ of patients. In the long-term follow-up study reported by Wilson and colleagues, $38 \%$ of patients were insulin independent at 1 year, and this declined to $27 \%$ at 5 years [73]. The number of patients with partial islet function defined in this study requiring less than $20 \mathrm{U}$ of insulin per day was $38 \%$ at 1 year and $35 \%$ at 5 years. Forty percent of patients required greater than $20 \mathrm{U}$ of insulin per day at 5 years after TP-IAT. The study suggested that the subgroup of patients who remain insulin independent included women and patients injected with a higher mean islet equivalent and a lower BMI [73].

Pain The primary goal for TP-IAT is to ameliorate the pain associated with chronic pancreatitis. The reported results of pain relief from TP-IAT is variable. A recent review on TPIAT demonstrated that in over 400 patients reported in the surgical literature from eight different centers, an average of $23 \%$ to over $80 \%$ of patients were pain free at the end of 1 year [76]. Sutherland and colleagues in the largest study reported to date showed that $94 \%$ of patients achieved complete and partial pain relief at 1 year after surgery. However, this data was limited by the short duration of follow-up, and only $46 \%$ of patients were narcotic free of the end of 1 year [77]. The Minnesota group recently reported on their longterm results of TP-IAT and found actuarial patient survival post-TP-IAT was $96 \%$ in adults and $98 \%$ in children at 1 year and 89 and $98 \%$ at 5 years, respectively. At 3 years, $30 \%$ were insulin independent ( $25 \%$ in adults, $55 \%$ in children) and $33 \%$ had partial function. Prior pancreas surgery lowered 
islet yield ( 2712 vs. $4077 / \mathrm{kg}, p=0.003$ ). Islet yield [ $<2500 / \mathrm{kg}$ (36\%), 2501-5000/kg (39\%), >5000/kg (24\%)] correlated with degree of function with insulin-independent rates at 3 years of 12,22 , and $72 \%$ and partial function of 33, 62, and $24 \%$ [52]. Pain is the primary reason for TP-IAT, and therefore it is interesting to note that in this study, after TPIAT by 2 years, only $59 \%$ had ceased using narcotics. While this study reported data over a 30 -year period, surprisingly the data for pain relief is only provided for 2 years and islet function for 3 years [52].

Wilson and colleagues in the largest long-term follow-up report showed that narcotic independence at 1 year was $55 \%$; however, this continued to improve to $73 \%$ at 5 years. In this study, a significant portion of the patients continued to require narcotic analgesia for pain at the end of 5 years [73].

It is interesting to note that the majority of reported studies with TP-IAT have shown that approximately 15 to $20 \%$ of patients have persistent pain unchanged from their preoperative status after TP-IAT, and in 3 to $5 \%$ of patients, the pain is worse after surgery compared to that before surgery. Qualityof-life assessments have shown an improvement from preoperative base baseline in $92 \%$ of patients at 1 year and $85 \%$ of patients after 5 years $[52,70,74-76]$. The findings that $20 \%$ of patients will have persistent pain and significant numbers of patients will continue to be on narcotic pain medication albeit reduced despite a total pancreatectomy $[52,70,74-76]$ underscore the complex nature of the pathophysiology of pain in chronic pancreatitis and the potential role of pain of central origin. These findings also raise the limitations of local solutions directed towards the pancreatic bed in selected patient subpopulations with chronic pancreatitis.

In patients in whom a future TP-IAT procedure is a consideration, pancreatic resection and pancreatic duct decompression procedures particularly the Puestow procedure may negatively impact islet yield and therefore should be used as the initial surgical procedure with caution. The Puestow procedure is a particular problem for TP-IAT since for adequate islet yield, the pancreatic duct is infused with a collection of mixed enzyme solution of collagenase and proteases to digest the exocrine tissue; this aspect of the islet isolation technique is compromised in a patient with prior Puestow procedure. Recently, Wilson et al. [74] reported their results with TP-IAT on patients who had previously undergone prior limited pancreatic resection or a pancreatic drainage procedure. Fifty percent of patients underwent prior pancreaticoduodenectomy, $17 \%$ distal pancreatectomy, $13 \%$ Frey, $13 \%$ Puestow, and $8 \%$ Berne procedures. Islet cell isolation was feasible with an islet cell autotransplantation of $4737 \pm 492 \mathrm{IEQ} / \mathrm{kg}$ body weight. Their median patient follow-up was 21.2 months. Before TP-IAT, patients required a mean of 120.8 morphine equivalent milligrams per day (MEQ/day), which improved to $48.5 \mathrm{MEQ}$ $(p<0.001)$ compared with preoperative requirements. Fortyfour percent achieved narcotic independence. All patients were able to achieve stable glycemic control with a mean insulin requirement of $16 \mathrm{U}$ per day. Twenty percent were insulin independent and mean C-peptide levels 6 months after TP-IAP were $0.91 \mathrm{ng} / \mathrm{mL}$ (range, 0.1-3.0). The SF-36 QOL survey administered postoperatively demonstrated improvement in all tested modules. This study showed that salvage TP-IAT is a feasible procedure in patients who have previously undergone a drainage procedure or a pancreatic resection for pain in chronic pancreatitis [74].

The reported results of pain relief and quality-of-life outcomes with TP-IAT are similar to that previously reported with surgical procedures for chronic pancreatitis such as Frey procedure, pancreaticoduodenectomy, and Beger procedure. While reported results from TP-IAT do not appear to be superior compared to surgical resection procedures, patient selection and indications are not comparable between the studies of TP-IAT and patients undergoing pancreatic resection procedures. TP-IAT should be considered as first-line treatment in patients with small duct disease and particularly patients with familial chronic pancreatitis (where risk of pancreatic cancer is significant). Since TP-IAT is associated with significant financial resource utilization and the potential for severe type $3 c$ diabetes and pancreatic malabsorption, these procedures should be not be primarily used in patients who are candidates for standard surgical procedures such as Frey and Beger procedure for chronic pancreatitis. We do not subscribe to Sutherland and colleagues' [52] contention that TP-IAT is the primary surgical option after failed endoscopic procedures in all patients requiring surgery for pain in chronic pancreatitis.

\section{Does Early Intervention Improve the Outcome for Surgery in Patients with Intractable Chronic Pain from Chronic Pancreatitis?}

The understanding of neurobiology of pain in chronic pancreatitis shows that pancreatic neuropathy with altered nociception and peripheral sensitization is an important mechanism for pain in chronic pancreatitis. Allowing pancreatic pain to persist for a prolonged period of time leads to central sensitization. Furthermore, many patients on chronic narcotics therapy also develop opioid-induced hyperalgesia, a state of nociceptive sensitization caused by exposure to opioids. Thus, there are multiple pathways in patients with intractable pain on opiates which can lead to a self-perpetuating pain state with allodynia and hyperalgesia, a condition that is very difficult to reverse with medical or surgical therapy. Clearly, the optimum period of intervention should be before the patient becomes addicted to narcotic medication and central sensitization develops from the pancreatic neuropathy [78].

Currently, a conservative step-up approach (medical therapy including prescribing of narcotics followed by endoscopic 
treatment and surgery if only both fail) is recommended for pain in chronic pancreatitis. As discussed above, the outcome of surgical procedures including total pancreatectomy is poor in patients who are addicted to narcotic medications, on prolonged treatment with narcotics, and who have had multiple endoscopic procedures over a long period of time. This is further supported by several studies that demonstrate good surgical outcomes in patients with early surgical intervention and before the patient is on chronic opiates. Ali et al. studied 266 patients undergoing surgery for intractable pain with chronic pancreatitis with median follow-up of 62 months. Factors that were independently associated with pain relief and less endocrine pancreatic insufficiency include surgery in patients who were not on opioids preoperatively, patients who had five or fewer endoscopic treatments prior to surgery, or where surgery was within 3 years of symptoms [53]. Terrace et al. in a review of 22 patients with the Frey procedure and 28 with Puestow procedure found that patients were significantly more likely to be pain free and require fewer subsequent hospital readmissions for pain following surgery if they were opiate free prior to surgery [79]. Van der Gaag et al. in a study of 223 consecutive patients found that daily opiate usage and a high number of preoperative endoscopic procedures were significantly associated with less favorable outcome after surgery for chronic pancreatitis [80]. A metaanalysis by Yang et al. showed that early surgery for pain in chronic pancreatitis was associated with an increased likelihood of complete postoperative pain relief and reduced risk of pancreatic insufficiency and low re-intervention rates [81].

The timing of intervention remains a dilemma for those involved in the treatment of patients with chronic pancreatitis. A large multicenter randomized trial is currently being conducted within the Dutch Pancreatitis Study Group: the ESCAPE trial (Early Surgery versus Optimal Current Step-Up Practice for Chronic Pancreatitis trial; ISRCTN45877994) that may help answer the question of whether early surgical intervention for chronic pancreatitis improves pain control and pancreatic function compared with the current step-up practice of medical, endoscopic, and finally surgical treatment in patients with chronic pancreatitis [47].

\section{Laparoscopic Surgical Procedures for Chronic Pancreatitis}

Laparoscopic techniques have been described for all of the surgical procedures utilized in the treatment of chronic pancreatitis including surgery for pseudocysts, hepaticojejunostomy for biliary bypass, Puestow-type lateral pancreaticojejunostomy, the Frey procedure (Fig. 3), and pancreatic head resection. Kurian and Gragner were the first to perform a successful laparoscopic Puestow procedure in a report of five cases [82]. Since then, several publications have shown the technical feasibility of this procedure [83-85]. The
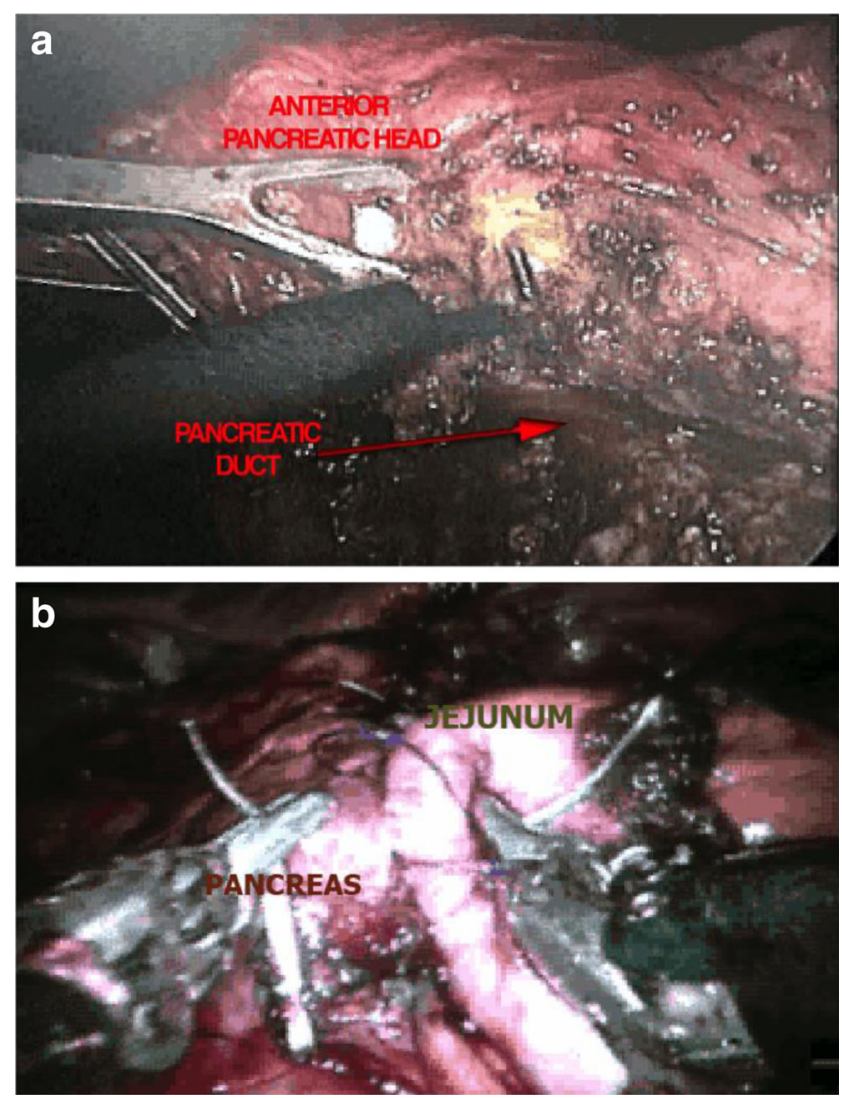

Fig. 3 Minimally invasive Frey procedure showing the resection of the anterior head of the pancreas (a) and reconstruction with robotic lateral pancreaticojejunostomy (b)

size and identification of the pancreatic duct are critical factors in performing a successful Puestow procedure. Laparoscopic ultrasound is very helpful in identifying the pancreatic duct, and most reported studies have utilized a size diameter of the pancreatic duct to exceed at least $8 \mathrm{~mm}$. Two of the larger studies of the Puestow procedure have originated from India where tropical pancreatitis presents with grossly dilated pancreatic ducts $[83,84]$. Palanivelu et al. operated in patients with a main pancreatic duct diameter of $10 \mathrm{~mm}$ or larger and reported no conversions to open surgery [84].

We reported the first laparoscopic Frey procedure and duodenum-preserving pancreatic head resection in a group of patients with chronic pancreatitis and IPMN of the head of the pancreas. Our technique of performing a pancreatic head resection differs from Beger's procedure in that we completely remove all of the pancreatic tissue in the duodenal C-loop preserving only the posterior pancreatic capsule and the duodenal vasculature that lies posteriorly on the posterior pancreatic capsule [86] (Fig. 4).

Complex laparoscopic pancreatic surgery has now evolved into mainstream practice with a number of centers in the USA and elsewhere performing advanced procedures such as the Whipple operation laparoscopically. It is our assessment that in the next decade, the vast majority of the surgical procedures 


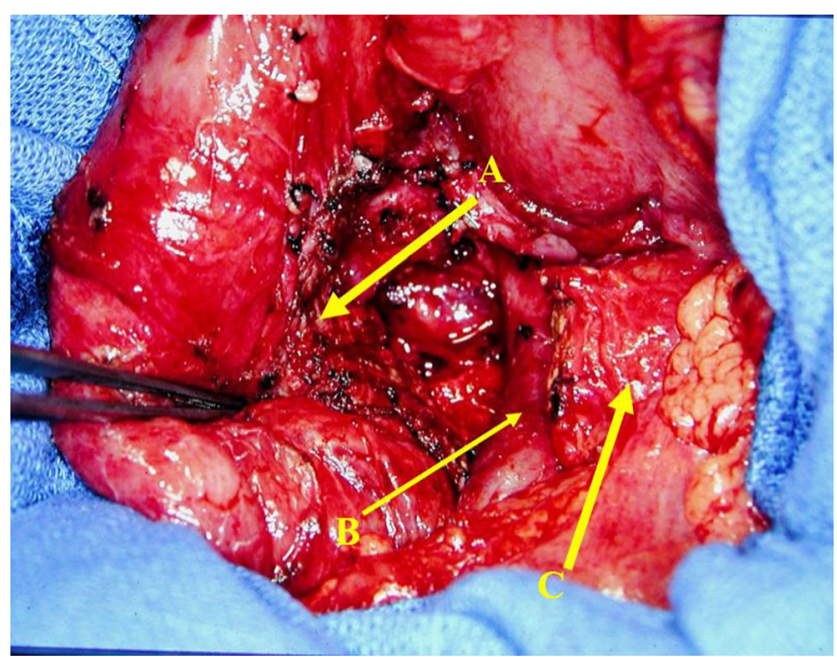

Fig. 4 Duodenum-preserving pancreatic head resection with complete resection of the head and uncinate process of the pancreas. $A$ small remnant of pancreas left on the C-loop of the pancreas, $B$ superior mesenteric vein, $C$ transected pancreas

for chronic pancreatitis will be performed laparoscopically as expertise with advanced laparoscopic pancreas surgery is gained in the wider community of hepatobiliary and pancreatic surgeons. We believe that caution needs to be practiced when using laparoscopic techniques in patients who have a large inflammatory mass in the head of the pancreas from chronic pancreatitis with extensive fibrotic encasement of the mesenteric vessels. However, with the exception of this group, patients with chronic pancreatitis are eminently suitable for laparoscopic surgery due to a smaller concern about the extent of resection for tumor-free tissue margins and an extensive tumor invading into the mesenteric vessels.

\section{Treatment of Thrombosis of the Splenic Vein, Superior Mesenteric Vein, or Portal Vein in Patients with Chronic Pancreatitis}

The incidence of mesenteric vein thrombosis (MVT) in chronic pancreatitis ranges from 5 to $37 \%$ in radiological and surgical studies $[87,88]$. A local inflammatory response associated with chronic pancreatitis is the primary cause for the development of vascular thromboses [89]. A recent study looked for the presence of thrombophilia and protein $\mathrm{C}$ and $\mathrm{S}$ and antithrombin deficiency, factor 2, factor 5, and JAK2 gene mutations, homocysteine, B12, and folate deficiencies, and the biological antiphospholipid syndrome was not detected [89]. A prospective study examined patients with chronic pancreatitis with ultrasonography which was followed by angiography or computed tomography (CT) if the ultrasound examination was positive. An overall incidence of mesenteric vein thrombosis was found to be $13 \%$ [8\% splenic vein (SVT), $6 \%$ portal vein PVT, and $1 \%$ superior mesenteric vein (SMT)] [90]. The presence of local complications from pancreatitis such as pseudocysts seems to increase the frequency of MVT, especially splenic vein thrombosis [89]. Limited data suggest that most of the patients will be asymptomatic from MVT and the rates of spontaneous recanalization are up to $30 \%$ predominantly for splenic vein thrombosis [87].

Isolated PVT/SVT or extension of the thrombus to the PV/ SMV territory is thought to be a more serious condition, and our experience suggests that the incidence of portal vein hypertension, ascites, and liver failure is significantly increased in the presence of extensive SVT/PVT. Furthermore, our experience with patients with SMV and PVT has been that the incidence of malabsorption, chronic gastrointestinal pain, and a failure to thrive is also high. At our institution, endovascular stenting of the portal and superior mesenteric vein in an attempt to restore blood flow has been performed successfully in a number of symptomatic patients with severe superior mesenteric vein thrombosis or portal vein thrombosis. Endovascular techniques may provide new options in the small group of patients with very difficult management issues and often a poor long-term outcome with extensive mesenteric vein thrombosis.

Surgical intervention is limited to performing a splenectomy preferably laparoscopically in patients with left-sided portal hypertension and gastric varices who develop a bleed from the varices. The incidence of variceal bleed is controversial; however, it appears to be small. Therefore, there is no benefit at present in performing prophylactic splenectomy in patients with left-sided portal hypertension.

\section{Surgery for Bile Duct Obstruction in Chronic Pancreatitis}

The prevalence of duct obstruction is between 1 and $40 \%$ in patients with chronic pancreatitis. In a patient with chronic pancreatitis with intractable pain, the treatment for the bile duct obstruction should be part of the surgical procedure for the chronic pain. A concomitant hepaticojejunostomy is performed together with the pancreatic drainage procedure or a duodenum-preserving pancreatic head resection for the pain.

In an otherwise asymptomatic patient who presents with bile duct obstruction in chronic pancreatitis, autoimmune pancreatitis should be ruled out by performing serum IgG4 levels and tissue staining for Ig4 antibody in endoscopic guided fineneedle aspirates of the pancreatic head [91].

The treatment of bile duct obstruction in patients who are asymptomatic without clinical jaundice is controversial. Controversy also exists for the management of an isolated elevated alkaline phosphatase level of biliary origin in a patient with chronic pancreatitis. The current consensus is that asymptomatic bile duct obstruction with or without an isolated elevation of the alkaline phosphatase level should be treated conservatively. Surgery is only indicated in a patient who has a rising alkaline phosphatase level or a patient who is 
otherwise asymptomatic but develops clinical jaundice [92]. The surgical procedure of choice is a laparoscopic Roux-en-Y hepaticojejunostomy $[93,94]$.

\section{Treatment of Patients with Pseudocysts from Chronic Pancreatitis}

Chronic pseudocysts are often associated with an underlying stricture or obstruction in the main pancreatic duct. Traditionally, the teaching has been to address the pancreatic ductal pathology either endoscopically or surgically to avoid pseudocyst recurrence from a persistent distal obstruction, and therefore status of the underlying pancreatic duct should be firmly established with confirmatory imaging before any planned intervention $[95,96]$.

Our approach has been to perform a definitive operation such as a Frey or a Beger procedure with a drainage procedure to the body and tail of the pancreas in patients who have chronic pain from their chronic pancreatitis. Patients who have a complicated pancreatic pseudocyst with compression of large vessels, gastric or duodenal outlet obstruction, bile duct obstruction, infection in the cyst, hemorrhage in the cyst, or a pancreaticopleural or pancreaticoperitoneal fistula should undergo surgical treatment for both the cyst and the underlying complication [96]. Patients who have incidentally discovered asymptomatic pseudocysts are expectantly observed if the cyst is under $6 \mathrm{~cm}$. For symptomatic cysts and cysts over $6 \mathrm{~cm}$, endoscopic techniques such as trans-papillary drainage or EUS-guided endoscopic cystogastrostomy are utilized as the initial treatment of choice $[97,98]$. Patients who fail endoscopic treatment or develop recurrent cysts are then treated surgically with laparoscopic cystogastrostomy, cystoduodenostomy, or a Roux-en-Y cystojejunostomy [98-100].

\section{Conclusions}

Chronic pancreatitis is a complex disorder that causes significant and chronic incapacity in patients and is a substantial burden on the society. Major advances have been made in the etiology and pathogenesis of this disease, and the role of genetic predisposition is increasingly coming to the fore. Advances in noninvasive diagnostic modalities now allow for better diagnosis of chronic pancreatitis at an early stage of the disease. The impact of these advances on surgical treatment is beginning to emerge, for example, patients with certain genetic predispositions may be better treated with total pancreatectomy versus lesser procedures. Considerable controversy remains with respect to the surgical management of chronic pancreatitis. Modern understanding of the neurobiology of pain in chronic pancreatitis suggests that a window of opportunity exists for effective treatment of the intractable pain after which central sensitization can lead to an irreversible pain syndrome in patients with chronic pancreatitis. Effective surgical procedures exist for chronic pancreatitis; however, the timing of surgery is unclear. For optimal treatment of patients with chronic pancreatitis, close collaboration between a multidisciplinary team including gastroenterologists, surgeons, and pain management physicians is needed.

Conflict of Interest The authors declare that they have no competing interests.

\section{References}

1. Muniraj T, Aslanian HR, Farrell J, Jamidar PA (2014) Chronic pancreatitis, a comprehensive review and update. Part I: epidemiology, etiology, risk factors, genetics, pathophysiology, and clinical features. Dis Mon 60(12):530-550

2. Balakrishnan V, Unnikrishnan AG, Thomas Vet al (2008) Chronic pancreatitis. A prospective nationwide study of 1,086 subjects from India. JOP 9(5):593-600

3. Brock C, Nielsen LM, Lelic D, Drewes AM (2013) Pathophysiology of chronic pancreatitis. World J Gastroenterol 19(42):7231-7240

4. Whitcomb DC (2010) Genetic aspects of pancreatitis. Annu Rev Med 61:413-424

5. Whitcomb DC (2013) Genetic risk factors for pancreatic disorders. Gastroenterology 144(6):1292-1302

6. Apte MV, Haber PS, Darby SJ et al (1999) Pancreatic stellate cells are activated by proinflammatory cytokines: implications for pancreatic fibrogenesis. Gut 44(4):534-541

7. Lee YA, Wallace MC, Friedman SL (2015) Pathobiology of liver fibrosis: a translational success story. Gut 64(5):830-841

8. Etemad B, Whitcomb DC (2001) Chronic pancreatitis: diagnosis, classification, and new genetic developments. Gastroenterology 120(3):682-707

9. Cote GA, Yadav D, Slivka A et al (2011) Alcohol and smoking as risk factors in an epidemiology study of patients with chronic pancreatitis. Clin Gastroenterol Hepatol 9(3):266-273, quiz e27

10. Mullady DK, Yadav D, Amann ST et al (2011) Type of pain, painassociated complications, quality of life, disability and resource utilisation in chronic pancreatitis: a prospective cohort study. Gut 60(1):77-84

11. Yadav D, Whitcomb DC (2010) The role of alcohol and smoking in pancreatitis. Nat Rev Gastroenterol Hepatol 7(3):131-145

12. Schneider A, Löhr JM, Singer MV (2007) The M-ANNHEIM classification of chronic pancreatitis: introduction of a unifying classification system based on a review of previous classifications of the disease. J Gastroenterol 42:101-119

13. Dufour MC, Adamson MD (2003) The epidemiology of alcoholinduced pancreatitis. Pancreas 27(4):286-290

14. Whitcomb DC (2012) Genetics of alcoholic and nonalcoholic pancreatitis. Curr Opin Gastroenterol 28(5):501-506

15. Maisonneuve P, Lowenfels AB, Müllhaupt B et al (2005) Cigarette smoking accelerates progression of alcoholic chronic pancreatitis. Gut 54(4):510-514

16. Rebours V, Vullierme MP, Hentic O et al (2012) Smoking and the course of recurrent acute and chronic alcoholic pancreatitis: a dose-dependent relationship. Pancreas 41(8):1219-1224

17. Imoto M, DiMagno EP (2000) Cigarette smoking increases the risk of pancreatic calcification in late-onset but not early-onset idiopathic chronic pancreatitis. Pancreas 21(2):115-119 
18. Comfort MW, Steinberg AG (1952) Pedigree of a family with hereditary chronic relapsing pancreatitis. Gastroenterology 21(1): 54-63

19. Whitcomb DC, Preston RA, Aston CE et al (1996) A gene for hereditary pancreatitis maps to chromosome $7 \mathrm{q} 35$. Gastroenterology 110(6):1975-1980

20. Midha S, Khajuria R, Shastri S, Kabra M, Garg PK (2010) Idiopathic chronic pancreatitis in India: phenotypic characterisation and strong genetic susceptibility due to SPINK1 and CFTR gene mutations. Gut 59(6):800-807

21. Chen JM, Ferec C (2009) Chronic pancreatitis: genetics and pathogenesis. Annu Rev Genomics Hum Genet 10:63-87

22. Tamura R, Ishibashi T, Takahashi S (2006) Chronic pancreatitis: MRCP versus ERCP for quantitative caliber measurement and qualitative evaluation. Radiology 238(3):920-928

23. Catalano MF, Sahai A, Levy M et al (2009) EUS-based criteria for the diagnosis of chronic pancreatitis: the Rosemont classification. Gastrointest Endosc 69(7):1251-1261

24. Balci NC, Smith A, Momtahen AJ et al (2010) MRI and S-MRCP findings in patients with suspected chronic pancreatitis: correlation with endoscopic pancreatic function testing (ePFT). J Magn Reson Imaging 31(3):601-606

25. Săftoiu A, Vilmann P, Gorunescu F et al (2011) Accuracy of endoscopic ultrasound elastography used for differential diagnosis of focal pancreatic masses: a multicenter study. Endoscopy 43(7): 596-603

26. Zuccaro P, Stevens T, Repas K et al (2009) Magnetic resonance cholangiopancreatography reports in the evaluation of chronic pancreatitis: a need for quality improvement. Pancreatology 9(6): 764-769

27. Nealon WH, Thompson JC (1993) Progressive loss of pancreatic function in chronic pancreatitis is delayed by main pancreatic duct decompression. A longitudinal prospective analysis of the modified Puestow procedure. Ann Surg 217(5):458-466, discussion 466-8

28. Manes G, Büchler M, Pieramico O, Di Sebastiano P, Malfertheiner $P$ (1994) Is increased pancreatic pressure related to pain in chronic pancreatitis? Int J Pancreatol 15(2):113-117

29. Ugljesić M, Bulajić M, Milosavljević T, Stimec B (1996) Endoscopic manometry of the sphincter of Oddi and pancreatic duct in patients with chronic pancreatitis. Int J Pancreatol 19(3): 191-195

30. Poulsen JL, Olesen SS, Malver LP, Frøkjær JB, Drewes AM (2013) Pain and chronic pancreatitis: a complex interplay of multiple mechanisms. World J Gastroenterol 19(42):7282-7291

31. White TT, Bourde J (1970) A new observation on human intraductal pancreatic pressure. Surg Gynecol Obstet 130(2): 275-278

32. Fasanella KE, Davis B, Lyons J et al (2007) Pain in chronic pancreatitis and pancreatic cancer. Gastroenterol Clin N Am 36(2): 335-364, ix

33. Demir IE, Tieftrunk E, Maak M, Friess H, Ceyhan GO (2011) Pain mechanisms in chronic pancreatitis: of a master and his fire. Langenbecks Arch Surg 396(2):151-160

34. D'Haese JG, Ceyhan GO, Demir IE, Tieftrunk E, Friess H (2014) Treatment options in painful chronic pancreatitis: a systematic review. HPB (Oxford) 16(6):512-521

35. Bockman DE, Buchler M, Malfertheiner P, Beger HG (1988) Analysis of nerves in chronic pancreatitis. Gastroenterology 94(6): 1459-1469

36. Ceyhan GO, Bergmann F, Kadihasanoglu M et al (2009) Pancreatic neuropathy and neuropathic pain - a comprehensive pathomorphological study of 546 cases. Gastroenterology 136(1):177-186, e1

37. Ceyhan GO, Demir IE, Rauch U et al (2009) Pancreatic neuropathy results in "neural remodeling" and altered pancreatic innervation in chronic pancreatitis and pancreatic cancer. Am J Gastroenterol 104(10):2555-2565

38. Demir I, Tieftrunk E, Maak M, Friess H, Ceyhan GO (2011) Pain mechanisms in chronic pancreatitis: of a master and his fire. Langenbeck's Arch Surg 396(2):151-160

39. Olesen SS, Frøkjær JB, Lelic D, Valeriani M, Drewes AM (2010) Pain-associated adaptive cortical reorganisation in chronic pancreatitis. Pancreatology 10(6):742-751

40. Frokjaer JB, Andersen LW, Brock C et al (2013) Altered brain microstructure assessed by diffusion tensor imaging in patients with diabetes and gastrointestinal symptoms. Diabetes Care 36(3):662-668

41. Olesen SS, Juel J, Graversen C et al (2013) Pharmacological pain management in chronic pancreatitis. World J Gastroenterol 19(42):7292-7301

42. Muniraj T, Aslanian HR, Farrell J, Jamidar PA (2015) Chronic pancreatitis, a comprehensive review and update. Part II: diagnosis, complications, and management. Dis Mon 61(1):5-37

43. Issa Y, van Santvoort HC, van Goor H et al (2013) Surgical and endoscopic treatment of pain in chronic pancreatitis: a multidisciplinary update. Dig Surg 30(1):35-50

44. Dumonceau JM, Delhaye M, Tringali A et al (2012) Endoscopic treatment of chronic pancreatitis: European Society of Gastrointestinal Endoscopy (ESGE) Clinical Guideline. Endoscopy 44(8):784-800

45. Díte P, Ruzicka M, Zboril V, Novotný I (2003) A prospective, randomized trial comparing endoscopic and surgical therapy for chronic pancreatitis. Endoscopy 35(7):553-558

46. Cahen DL, Gouma DJ, Laramée P et al (2011) Long-term outcomes of endoscopic vs surgical drainage of the pancreatic duct in patients with chronic pancreatitis. Gastroenterology 141(5):1690 1695

47. Ahmed Ali U, Issa Y, Bruno MJ et al (2013) Early surgery versus optimal current step-up practice for chronic pancreatitis (ESCAPE): design and rationale of a randomized trial. BMC Gastroenterol 13:49

48. Puestow CB, Gillesby WJ (1958) Retrograde surgical drainage of pancreas for chronic relapsing pancreatitis. AMA Arch Surg 76(6):898-907

49. Partington PF, Rochelle RE (1960) Modified Puestow procedure for retrograde drainage of the pancreatic duct. Ann Surg 152: $1037-1043$

50. Frey CF, Smith GJ (1987) Description and rationale of a new operation for chronic pancreatitis. Pancreas 2(6):701-707

51. Beger HG, Krautzberger W, Bittner R, Büchler M, Limmer J (1985) Duodenum-preserving resection of the head of the pancreas in patients with severe chronic pancreatitis. Surgery 97(4):467473

52. Sutherland DE, Radosevich DM, Bellin MD et al (2012) Total pancreatectomy and islet autotransplantation for chronic pancreatitis. J Am Coll Surg 214(4):409-424, discussion 424-6

53. Ahmed Ali U, Nieuwenhuijs VB, van Eijck CH et al (2012) Clinical outcome in relation to timing of surgery in chronic pancreatitis: a nomogram to predict pain relief. Arch Surg 147(10): 925-932

54. O'Neil SJ, Aranha GV (2003) Lateral pancreaticojejunostomy for chronic pancreatitis. World J Surg 27(11):1196-1202

55. Prinz RA, Greenlee HB (1981) Pancreatic duct drainage in 100 patients with chronic pancreatitis. Ann Surg 194(3):313-320

56. Izbicki JR, Bloechle C, Knoefel WT, Rogiers X, Kuechler T (1999) Surgical treatment of chronic pancreatitis and quality of life after operation. Surg Clin N Am 79(4):913-944

57. Bachmann K, Tomkoetter L, Erbes J et al (2014) Beger and Frey procedures for treatment of chronic pancreatitis: comparison of outcomes at 16-year follow-up. J Am Coll Surg 219(2):208-216 
58. Negi S, Singh A, Chaudhary A (2010) Pain relief after Frey's procedure for chronic pancreatitis. Br J Surg 97(7):1087-1095

59. Roch A, Teyssedou J, Mutter D, Marescaux J, Pessaux P (2014) Chronic pancreatitis: a surgical disease? Role of the Frey procedure. World J Gastrointest Surg 6(7):129-135

60. Strate T, Bachmann K, Busch P et al (2008) Resection vs drainage in treatment of chronic pancreatitis: long-term results of a randomized trial. Gastroenterology 134(5):1406-1411

61. Strate T, Taherpour Z, Bloechle C et al (2005) Long-term followup of a randomized trial comparing the Beger and Frey procedures for patients suffering from chronic pancreatitis. Ann Surg 241(4): 591-598

62. Yin Z, Sun J, Yin D, Wang J (2012) Surgical treatment strategies in chronic pancreatitis: a meta-analysis. Arch Surg 147(10):961-968

63. Gestic MA, Callejas-Neto F, Chaim EA et al (2011) Surgical treatment of chronic pancreatitis using Frey's procedure: a Brazilian 16-year single-centre experience. HPB (Oxford) 13(4):263-271

64. Falconi M, Bassi C, Casetti L et al (2006) Long-term results of Frey's procedure for chronic pancreatitis: a longitudinal prospective study on 40 patients. J Gastrointest Surg 10(4):504-510

65. Frey CF, Amikura K (1994) Local resection of the head of the pancreas combined with longitudinal pancreaticojejunostomy in the management of patients with chronic pancreatitis. Ann Surg 220(4):492-504, discussion 504-7

66. Izbicki JR, Bloechle C, Broering DC et al (1998) Extended drainage versus resection in surgery for chronic pancreatitis: a prospective randomized trial comparing the longitudinal pancreaticojejunostomy combined with local pancreatic head excision with the pylorus-preserving pancreatoduodenectomy. Ann Surg 228(6):771-779

67. Farkas G, Leindler L, Daróczi M, Farkas G Jr (2006) Prospective randomised comparison of organ-preserving pancreatic head resection with pylorus-preserving pancreaticoduodenectomy. Langenbecks Arch Surg 391(4):338-342

68. Buchler MW, Friess H, Müller MW, Wheatley AM, Beger HG (1995) Randomized trial of duodenum-preserving pancreatic head resection versus pylorus-preserving Whipple in chronic pancreatitis. Am J Surg 169(1):65-69, discussion 69-70

69. Izbicki JR, Bloechle C, Knoefel WT et al (1997) Drainage versus resection in surgical therapy of chronic pancreatitis of the head of the pancreas: a randomized study. Chirurg 68(4):369-377

70. Sutherland DE, Matas AJ, Najarian JS (1978) Pancreatic islet cell transplantation. Surg Clin N Am 58(2):365-382

71. Bellin MD, Freeman ML, Gelrud A et al (2014) Total pancreatectomy and islet autotransplantation in chronic pancreatitis: recommendations from PancreasFest. Pancreatology 14(1):27-35

72. Bellin MD, Gelrud A, Arreaza-Rubin G et al (2015) Total pancreatectomy with islet autotransplantation: summary of an NIDDK workshop. Ann Surg 261(1):21-29

73. Wilson GC, Sutton JM, Abbott DE et al (2014) Long-term outcomes after total pancreatectomy and islet cell autotransplantation: is it a durable operation? Ann Surg 260(4):659-665, discussion 665-7

74. Wilson GC, Sutton JM, Smith MT et al. (2015) Completion pancreatectomy and islet cell autotransplantation as salvage therapy for patients failing previous operative interventions for chronic pancreatitis. Surgery

75. Witkowski P, Savari O, Matthews JB (2014) Islet autotransplantation and total pancreatectomy. Adv Surg 48: 223-233

76. Kesseli SJ, Smith KA, Gardner TB (2015) Total pancreatectomy with islet autologous transplantation: the cure for chronic pancreatitis? Clin Transl Gastroenterol 6:e73
77. Farney AC, Najarian JS, Nakhleh RE et al (1991) Autotransplantation of dispersed pancreatic islet tissue combined with total or near-total pancreatectomy for treatment of chronic pancreatitis. Surgery 110(2):427-437, discussion 437-9

78. Lee M, Silverman SM, Hansen H, Patel VB, Manchikanti L (2011) A comprehensive review of opioid-induced hyperalgesia. Pain Physician 14(2):145-161

79. Terrace JD, Paterson HM, Garden OJ, Parks RW, Madhavan KK (2007) Results of decompression surgery for pain in chronic pancreatitis. HPB (Oxford) 9(4):308-311

80. van der Gaag NA, van Gulik TM, Busch OR et al (2012) Functional and medical outcomes after tailored surgery for pain due to chronic pancreatitis. Ann Surg 255(4):763770

81. Yang CJ, Bliss LA, Schapira EF et al (2014) Systematic review of early surgery for chronic pancreatitis: impact on pain, pancreatic function, and re-intervention. J Gastrointest Surg 18(10):18631869

82. Kurian MS, Gagner M (1999) Laparoscopic side-to-side pancreaticojejunostomy (Partington-Rochelle) for chronic pancreatitis. J Hepatobiliary Pancreat Surg 6(4):382-386

83. Tantia O, Jindal MK, Khanna S, Sen B (2004) Laparoscopic lateral pancreaticojejunostomy: our experience of 17 cases. Surg Endosc 18(7):1054-1057

84. Palanivelu C, Shetty R, Jani K et al (2006) Laparoscopic lateral pancreaticojejunostomy: a new remedy for an old ailment. Surg Endosc 20(3):458-461

85. Khaled YS, Ammori BJ (2014) Laparoscopic lateral pancreaticojejunostomy and laparoscopic Berne modification of Beger procedure for the treatment of chronic pancreatitis: the first UK experience. Surg Laparosc Endosc Percutan Tech 24(5): e178-e182

86. Parekh D, Berrera K (2010) Laparoscopic assisted duodenum-preserving pancreatic head resection and total pancreatectomy: description of the technique and indications. In ACS multimedia atlas of surgery: pancreas surgery volume, A. Asbun, Fuchshuber, P.R., Editor., American College of Surgeons

87. Nadkarni NA, Khanna S, Vege SS (2013) Splanchnic venous thrombosis and pancreatitis. Pancreas 42(6):924-931

88. Butler JR, Eckert GJ, Zyromski NJ et al (2011) Natural history of pancreatitis-induced splenic vein thrombosis: a systematic review and meta-analysis of its incidence and rate of gastrointestinal bleeding. HPB (Oxford) 13(12):839-845

89. Rebours V, Boudaoud L, Vullierme MP et al (2012) Extrahepatic portal venous system thrombosis in recurrent acute and chronic alcoholic pancreatitis is caused by local inflammation and not thrombophilia. Am J Gastroenterol 107(10):1579-1585

90. Bernades P, Baetz A, Lévy P et al (1992) Splenic and portal venous obstruction in chronic pancreatitis. A prospective longitudinal study of a medical-surgical series of 266 patients. Dig Dis Sci 37(3):340-346

91. Hart PA, Zen Y, Chari ST (2015) Recent advances in autoimmune pancreatitis. Gastroenterology 149(1):39-51

92. Saluja SS, Kalayarasan R, Mishra PK et al (2014) Chronic pancreatitis with benign biliary obstruction: management issues. World J Surg 38(9):2455-2459

93. Regimbeau JM, Fuks D, Bartoli E et al (2012) A comparative study of surgery and endoscopy for the treatment of bile duct stricture in patients with chronic pancreatitis. Surg Endosc 26(10):2902-2908

94. Kohan G, Ocampo CG, Zandalazini HI et al (2015) Laparoscopic hepaticojejunostomy and gastrojejunostomy for palliative treatment of pancreatic head cancer in 48 patients. Surg Endosc 29(7):1970-1975 
95. Cannon JW, Callery MP, Vollmer CM Jr (2009) Diagnosis and management of pancreatic pseudocysts: what is the evidence? J Am Coll Surg 209(3):385-393

96. Aghdassi A, Mayerle J, Kraft M et al (2008) Diagnosis and treatment of pancreatic pseudocysts in chronic pancreatitis. Pancreas 36(2):105-112

97. Dumonceau JM, Macias-Gomez C (2013) Endoscopic management of complications of chronic pancreatitis. World $\mathrm{J}$ Gastroenterol 19(42):7308-7315
98. Zerem E, Hauser G, Loga-Zec S et al (2015) Minimally invasive treatment of pancreatic pseudocysts. World J Gastroenterol 21(22):6850-6860

99. Gumaste VV, Aron J (2010) Pseudocyst management: endoscopic drainage and other emerging techniques. J Clin Gastroenterol 44(5):326-331

100. Nakeeb A (2009) Laparoscopic pancreatic resections. Adv Surg 43:91-102 